INFLAMMATION AND INFLAMMATORY BOWEL DISEASE

\title{
Changing pattern of paediatric inflammatory bowel disease in northern Stockholm 1990-2001
}

\author{
H Hildebrand, Y Finkel, L Grahnquist, J Lindholm, A Ekbom, J Askling
}

Gut 2003;52:1432-1434

See end of article for authors' affiliations

Correspondence to: Dr H Hildebrand, Astrid Lindgren Children's Hospital, SE 17176 Stockholm, Sweden; hans.hildebrand@ks.se

Accepted for publication 30 May 2003

\begin{abstract}
Background: An increased incidence of paediatric Crohn's disease was reported recently by our group. Aims: To assess the incidence and characteristics of inflammatory bowel disease (IBD) in northern Stockholm between 1990 and 2001.

Methods: All records of individuals 0-15 years of age with suspected IBD in the population based catchment area of 180000 individuals were scrutinised using defined diagnostic criteria. Patient files were searched for relatives with IBD, and for concomitant autoimmune diseases.

Results: A total of 152 children were diagnosed with IBD, corresponding to an overall incidence (per 100000 ) of IBD of 7.4. The incidence of Crohn's disease (CD) was 4.9, ulcerative colitis (UC) 2.2, and indeterminate colitis 0.2 . Between 1990 and 2001, there was a marked increase in the incidence of CD while the incidence of UC was almost unchanged, leading to a net increase in the overall occurrence of IBD. There was a male dominance of CD. Fourteen per cent and $11 \%$ of patients with CD and UC, respectively, had a first or second degree relative with IBD. Eighteen per cent and $10 \%$ of patients with $C D$ and UC, respectively, had a concomitant autoimmune disease. Ten patients with CD (10\%) underwent surgery.

Conclusions: The incidence of CD has increased in northern Stockholm. The current incidence is higher than that reported from other areas. Our results suggest a shift in presentation and diagnosis from UC towards $C D$, but also a net increase in IBD. Concomitant autoimmune disorders and family history are common in paediatric IBD.
\end{abstract}

\section{SUBJECTS AND METHODS}

This prospective study comprised all residents less than 16 years of age in northern Stockholm County (180 000 individuals). Between 1990 and 2001, all children with suspected IBD were referred to our department for evaluation following an agreement with all doctors in the catchment area. All children were examined with colonoscopy, and most $(78 \%)$ with upper gastrointestinal endoscopy, including biopsies for histology. The small intestine was examined by either $x$ ray or scintigraphy. For the diagnosis of ulcerative colitis (UC), CD, and indeterminate colitis (IC), strict criteria were used ${ }^{2}{ }^{3}$ and IC was only used when a distinct diagnosis of UC or CD could not be established. Trends or differences in incidence were evaluated using Poisson regression models, including calendar period of diagnosis, sex, and age.

\section{RESULTS}

During 1990-2001, 152 children and adolescents were diagnosed with IBD (102 with CD, 45 with UC, and five with IC). Mean age at diagnosis of $C D$ was 11.1 years (minimun-maximum 2.5-15.9), mean age at diagnosis of UC was 12.8 years (6.5-15.8), and mean age at diagnosis of IC was 8.3 years $(0.3-10.6)$.

In 21 children (14\%), the initial IBD diagnosis was changed; 15 children had their diagnosis changed from UC to $\mathrm{CD}$, five from IC to $\mathrm{CD}$, and one from IC to UC. The new diagnosis was established after repeated colonoscopies in 19 children, at surgery in one, and after upper gastrointestinal endoscopy in one.

In CD, 56 children ( $55 \%$ ) had disease confined to the large intestine, 26 children (25\%) had both small and large bowel involvement, and 17 children (17\%) had involvement of the upper gastrointestinal tract (oesophagus, stomach, and/or duodenum) in combination with the small or large intestine (table 1). Two children (2\%) had disease confined to the small intestine. One child had only oral localisation. Fifteen children (15\%) with CD had fistulae. In UC, 33 children (73\%) had total colitis and 12 children $(27 \%)$ had left sided colitis.

The overall incidence (per 100000 ) of IBD was 7.4 (95\% confidence interval 6.2-8.6). The overall incidence of CD was 4.9 (4.0-6.0), the incidence of UC was $2.2(1.6-2.9)$, and the incidence of IC was $0.2(0.1-0.6)$. During the study period, the incidence of IBD increased $(p=0.0014)$ (table 2). The incidence of CD increased from $1.7(0.7-3.3)$ in 1990-1992 to $3.5(2.1-5.5)$ in $1993-1995$, to $5.6(3.8-8.1)$ in 1996-1998, and to $8.4(6.2-11.3$ ) in 1999-2001 (p for trend 1990-2001 $<0.0001$, the positive trend was present both among individuals aged 5-9 years and 10-15 years, respectively). Apart from a non-significantly higher point estimate during 1990-1992, the incidence of UC remained stable throughout the study period. The ratio of CD to UC increased from 0.5 in 1990-1992, to 2.0 in 1993-1995, 3.0 in 1996-1998, and to 4.6 in 1999-2001. Males had a significantly higher incidence of IBD than females $(p=0.0059)$ due to a near doubled and significantly higher incidence of CD $(p=0.0144)$.

Abbreviations: $C D$, Crohn's disease; IBD, inflammatory bowel disease; UC, ulcerative colitis; IC, indeterminate colitis 
Table 1 Localisation of inflammation in 102 patients with Crohn's disease

\begin{tabular}{llllllr}
\hline Year & Oral & Small intestine & $\begin{array}{l}\text { Distal ileum and } \\
\text { colon }\end{array}$ & Colon & $\begin{array}{l}\text { Combined } \\
\text { localisations* }\end{array}$ & All \\
\hline $1990-1995$ & 0 & 1 & 11 & 11 & 3 & 26 \\
$1996-2001$ & 1 & 1 & 15 & 45 & 14 & 76 \\
$1990-2001$ & 1 & 2 & 26 & 56 & 17 & 102 \\
\hline
\end{tabular}

Values are given divided into two six year periods and for the whole study period.

*Combined localisations indicate that inflammation was found at both upper and lower endoscopy.

Table 2 Incidence (with 95\% confidence intervals) of inflammatory bowel disease (IBD) in children and adolescents 0-15 years of age in northern Stockholm 1990-2001

\begin{tabular}{|c|c|c|c|c|c|}
\hline & \multirow[b]{2}{*}{$\mathbf{n}$} & \multicolumn{4}{|c|}{ Incidence per 100000} \\
\hline & & IBD & $C D$ & UC & IC \\
\hline $\mathrm{n}$ & & 152 & 102 & 45 & 5 \\
\hline Overall & 152 & $7.4(6.2-8.6)$ & $4.9(4.0-6.0)$ & $2.2(1.6-2.9)$ & $0.2(0.1-0.6)$ \\
\hline \multicolumn{6}{|l|}{ Year } \\
\hline $1990-1992$ & 25 & $5.2(3.4-7.7)$ & $1.7(0.7-3.3)$ & $3.3(1.9-5.4)$ & $0.2(0.0-1.2)$ \\
\hline $1993-1995$ & 29 & $5.6(3.8-8.1)$ & $3.5(2.1-5.5)$ & $1.8(0.8-3.3)$ & $0.4(0.0-1.4)$ \\
\hline $1996-1998$ & 41 & $7.7(5.5-10.5)$ & $5.6(3.8-8.1)$ & $1.9(0.9-3.5)$ & $0.2(0.0-1.0)$ \\
\hline $1999-2001$ & 57 & $10.5(7.5-13.5)$ & $8.4(6.2-11.3)$ & $1.8(0.9-3.4)$ & $0.2(0.0-1.0)$ \\
\hline \multicolumn{6}{|l|}{ Age $(y)$} \\
\hline $0-4$ & 6 & $0.9(0.3-1.9)$ & $0.7(0.2-1.7)$ & $0.0(0.0-0.0)$ & $0.1(0.0-0.8)$ \\
\hline $5-9$ & 38 & $5.7(4.0-7.8)$ & $4.5(3.0-6.4)$ & $1.1(0.4-2.2)$ & $0.2(0.0-0.8)$ \\
\hline $10-15$ & 108 & $15.2(12.5-18.3)$ & $9.4(7.3-17.4)$ & $5.3(3.8-7.3)$ & $0.4(0.1-1.2)$ \\
\hline \multicolumn{6}{|c|}{$10.2(12.0-10.0)$} \\
\hline Male & 91 & $8.5(7.3-11.1)$ & $6.2(5.0-8.2)$ & $2.2(1.5-3.5)$ & $0.2(0.0-0.7)$ \\
\hline Female & 61 & $6.0(4.8-7.5)$ & $3.6(2.5-4.8)$ & $2.1(1.2-3.0)$ & $0.5(0.1-0.8)$ \\
\hline
\end{tabular}

Fourteen children with CD (14\%) had at least one first or second degree relative with IBD ( $12 \mathrm{CD}$, five UC). Five children with UC $(11 \%)$ had at least one first or second degree relative with IBD (three CD, four UC). Concomitant autoimmune diseases (primary sclerosing cholangitis, chronic polyarthritis, coeliac disease, pulmonary fibrosis, pancreatitis, systemic lupus erythematosus, and thyroiditis) were more common in CD (18\%) than in UC $(10 \%)$. Surgical treatment was performed in 10 children with CD. No child with UC or IC underwent surgery.

\section{DISCUSSION}

The increasing incidence of $\mathrm{CD}$, and the stable incidence of UC, corroborates earlier reports from the UK. ${ }^{4-6}$ Our incidence of CD is $50 \%$ higher (but that of UC is similar) than that of the hitherto largest (cross sectional) study. ${ }^{7}$ The predominance of CD over UC is in agreement with (non-population based) studies from North America ${ }^{8-10}$ but in contrast with earlier Scandinavian studies. ${ }^{2}{ }^{11-13}$ The difference may however be explained by temporal differences as our incidences during the same calendar period as that of the most recent Swedish study are similar. ${ }^{3}$ The higher incidence among males is similar to that of previous paediatric, ${ }^{70}$ but not that of adult studies. ${ }^{14}$ In contrast with most previous reports ${ }^{4}{ }^{15}$ - except for two recent studies ${ }^{10}{ }^{16}$ - colonic CD or colon combined with upper gastrointestinal tract involvement was common $(80 \%)$ whereas exclusive small bowel CD was not.

In our study, the diagnostic criteria remained the same during the study period but the number of endoscopies per patient and the proportion of upper gastrointestinal endoscopies increased over time. This may have led to a change in the distribution of subtypes of IBD..$^{3} 121718$ Our incidence of IC is the lowest reported, most likely as a consequence of repeated endoscopic investigations eventually establishing a diagnosis of (mostly) CD. Abnormalities compatible with CD found at upper gastrointestinal endoscopy affected the final diagnosis in only two patients; most children with CD had their diagnosis based on colonoscopy. Analysis of the initial versus the final diagnosis of IBD in our study revealed that reclassification contributed to an overall $24 \%$ increase in the incidence of CD (a doubling of the incidence before 1995, and a marginal effect thereafter), but served as an incomplete explanation for the time trends, sex difference, and dominance of CD over UC. However, this study demonstrates a net increase in the incidence of IBD which cannot be attributed to shifts in the incidences of subgroups.

Other autoimmune diseases were common, especially in comparison with values in adult IBD. ${ }^{19}$ Surgical treatment was comparatively rare, ${ }^{2-413}$ possibly because of early diagnosis and rapid institution of therapy. ${ }^{20-24}$

Our study has confirmed and characterised a marked increase in the incidence of $\mathrm{CD}$, indicated the importance of repeated re-evaluation, but also the limited influence of changes in classification of IBD on temporal trends. Of special interest were the high proportion of colonic CD and the high prevalence of autoimmune conditions in paediatric IBD, both of which warrant further investigation.

\section{Authors' affiliations}

H Hildebrand, Y Finkel, L Grahnquist, J Lindholm, A Ekbom, J Askling, Department of Women and Child Health, Astrid Lindgren Children's Hospital, Stockholm, Sweden

\section{REFERENCES}

1 Askling J, Grahnquist L, Ekbom A, et al. Incidence of paediatric Crohn's disease in Stockholm, Sweden. Lancet 1999;354:1179.

2 Chong SKF, Blackshaw AJ, Boyle S, et al. Histological diagnosis of chronic inflammatory bowel disease in childhood. Gut 1985;26:55-9.

3 Hildebrand $\mathrm{H}$, Brydolf $M$, Holmquist $L$, et al. Incidence and prevalence of inflammatory bowel disease in children in southwestern Sweden. Acta Paediatr 1994;83:640-5.

4 Lindberg $E$, Lindquist $B$, Holmquist $L$, et al. Inflammatory bowel disease in children and adolescents in Sweden, 1984-1995. JPGN 2000;30: 259-64. 
5 Barton JR, Gillon S, Ferguson A. Incidence of inflammatory bowel disease in Scottish children between 1968 and 1983; marginal fall in ulcerative colitis, three-fold rise in Crohn's disease. Gut 1989;30:618-22.

6 Cosgrove M, Al-Atia R, Jenkins HR. The epidemiology of paediatric inflammatory bowel disease. Arch Dis Child 1996:74:460-1.

7 Armitage E, Drummond HE, Wilson DC, et al. Increasing incidence of both juvenile-onset Crohn's disease and ulcerative colitis in Scotland. Eur J Gastroenterol Hepatol 2001;13:1439-47.

8 Sawczenko A, Sandhu BK, Logan RFA, et al. Prospective survey of childhood inflammatory bowel disease in the British Isles. Lancet 2001;357:1093-4.

9 Kirschner BS. Inflammatory bowel disease in childhood. In: Bouchier IAD, Allan RN, Hodgson HJF, et al, eds. Textbook of gastroenterology, London: Baillière Tindall, 1984:999-1004.

10 Seidman E, Morin CL, Weber AM, et al. Inflammatory bowel disease in children. In: Freeman HJ, eds. Inflammatory bowel disease, vol 2. Boca Raton: CRC Press, 1989:217-47.

11 Griffiths AM, Buller HB. Inflammatory bowel disease. In Walker WA, Durie PR Hamilton JR, et al, eds. Pediatric gastrointestinal disease. Hamilton: $\mathrm{BC}$ Decker, 2000:613-52.

12 Olafsdottir EJ, Fluge G, Haug K. Chronic inflammatory bowel disease in children in Western Norway. JPGN 1989;8:454-8.

13 Hildebrand $\mathrm{H}$, Fredrikzon B, Holmquist L, et al. Chronic inflammatory bowel disease in children and adolescents in Sweden. JPGN 1991; 13:293-7.

14 Langholz E, Munkholm P, Davidsen M, et al. Inflammatory bowel diseases with onset in childhood: clinical features, morbidity, and mortality in a regional cohort. Scand J Gastroenterol 1997;32:139-47.
15 Logan RFA. Inflammatory bowel disease incidence: up, down or unchanged? Gut 1998;42:309-11.

16 Polito JM, Chlds B, Mellits ED, et al. Crohn's disease: influence of age at diagnosis on site and clinical type of disease. Gastroenterology $1996 ; 111: 580-6$

17 Mamula P, Telega GW, Markowitz JE, et al. Inflammatory bowel disease in children 5 years of age and younger. Am J Gastroenterol 2002;97:2005-10.

18 Holmquist L, Rudic N, Åhrén C, et al. The diagnostic value of colonoscopy compared with rectosigmoidoscopy in children and adolescents with symptoms of chronic inflammatory bowel disease of the colon. Scand J Gastroenterol 1988;23:577-84.

19 Moum B, Ekbom A, Varn MH, et al. Inflammatory bowel disease: reevaluation of the diagnosis in a prospective population based study in the south eastern Norway. Gut 1997:40:328-32.

20 Snook JA, de Silva HJ, Jewell DP. The association of autoimmune disorders with inflammatory bowel disease. Q J Med 1989;269:835-40.

21 Davies G, Evans CM, Shand WS, et al. Surgery for Crohn's disease in childhood: influence of site of disease and operative procedure on outcome. Br J Surg 1990:77:891-4.

22 D'Haens G, Geboes K, Ponette E, et al. Healing of severe recurrent ileitis with azathioprin therapy in patients with Crohn's disease. Gastroenterology 1997; 112:1475-81.

23 Murch SH, Walker-Smith JA. Nutrition in inflammatory bowel disease. Bailliere's Clin Gastroenterol 1998;12:719-38.

24 Markowitz J, Grancher K, Kohn, et al, and the pediatric 6MP collaborative group. A multicenter trial of 6-mercaptopurine and prednisone in children with newly diagnosed Crohn's disease. Gastroenterology 2000;119:895-902.

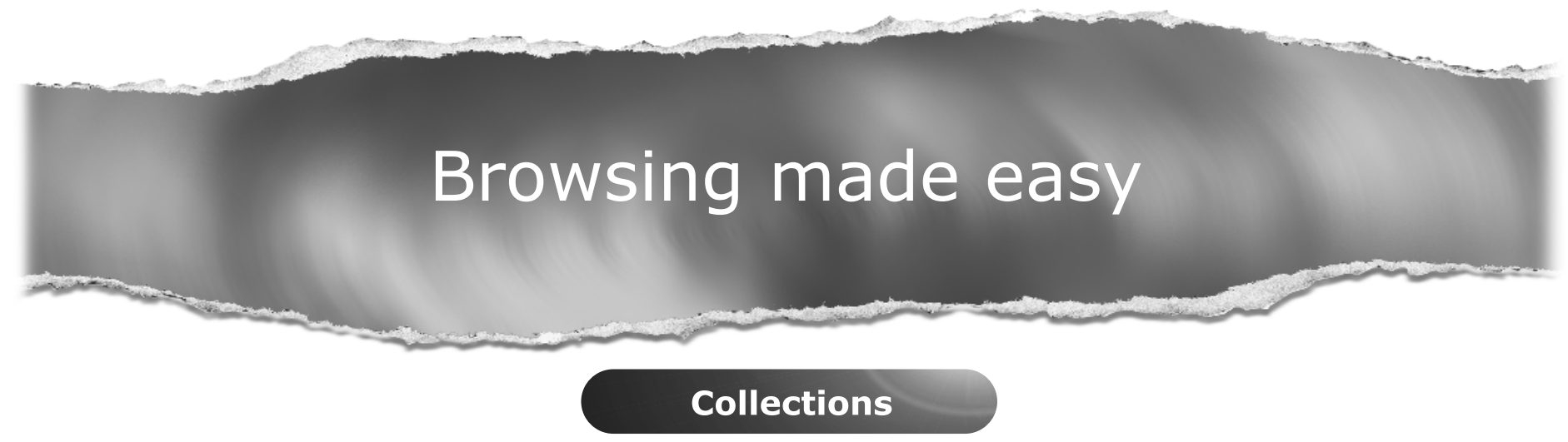

With a single click Collections allows you to find all articles that have been published in your chosen subject. Select from over 200 clinical and non-clinical topic collections and/or cross search other specialist journals, the BMJ and Cochrane Reviews

www.gutjnl.com 